\title{
Exposing Seeds of Sarcococca confusa to Increased Concentrations and Durations of Ethyl Methanesulfonate Reduced Seed Germination, Twinning, and Plant Size
}

\author{
Tyler Hoskins and Ryan N. Contreras \\ Department of Horticulture, Oregon State University, 4017 Agricultural and \\ Life Sciences, Corvallis, OR 97331
}

Additional index words. apomixis, Buxaceae, fragrant sweetbox, mutagenesis, mutation breeding

\begin{abstract}
Sweetbox (Sarcococca confusa) is an evergreen shrub valued for attractive foliage, winter fragrance, black fruit, as well as shade and drought tolerance. The high degree of apomixis in Sarcococca limits the effectiveness of conventional breeding practices. However, mutation breeding may be a valuable tool to induce variation in seedling crops. As such, a study was conducted to expose seeds of $S$. confusa to ethyl methanesulfonate (EMS) at varying concentrations and exposure durations, and to evaluate the effects on seed germination, growth, and relative frequency of polyembryony. In 2010, seeds of $S$. confusa were treated with $0 \%, 0.2 \%, 0.4 \%, 0.8 \%$, and $1.2 \%$ EMS for 24 and 48 hours. Seeds were sown and the relative germination and occurrence of polyembryony were recorded. Seedlings were later evaluated for size and phenotypic variation in the subsequent growing seasons. Percent germination was found to decrease with increasing EMS rates in the 24- and 48-hour treatments. The occurrence of polyembryony also decreased with increasing EMS rates in the 24-hour treatment but was observed to be greatest at $0.2 \%$ EMS. No significant differences in plant size index (SI) were found after four growing seasons. When mature, seeds were collected from any plants that bore fruit in each treatment and were then sown. The percentage of plants that bore fruit in each treatment decreased with increasing EMS rates, although the germination rate of these seeds did not differ. A chlorophyll mutant and several dwarf forms were identified in this population as well. They have been propagated asexually for future evaluation as new cultivars. This study demonstrates the utility of chemical mutagenesis to induce phenotypic variation in $S$. confusa while reducing the rate of polyembryony.
\end{abstract}

Sweetbox (Sarcococca confusa) is an evergreen shrub with attractive foliage in Buxaceae that requires shade and is relatively compact, making it an excellent choice for foundation plantings. Its white flowers are apetalous, sweetly fragrant, borne during winter, and give rise to glossy black drupes. In addition to its numerous ornamental attributes, it is regarded as highly drought tolerant (Dirr, 2009), which allows it to thrive in dry shade, which is a challenging landscape site for most plants. More compact forms of this species may be preferred for modern landscapes or container gardens. However, reports of apomixis in Sarcococca present challenges to breeding. Dirr (2009) reported

\footnotetext{
Received for publication 29 July 2019. Accepted for publication 11 Sept. 2019.

We wish to thank Mara Friddle for her technical support and the Oregon Department of Agriculture for partial funding of this research.

T.H. is a Faculty Research Assistant.

R.N.C. is an Associate Professor.

R.N.C. is the corresponding author. E-mail: ryan. contreras@oregonstate.edu.
}

mixis occurs, at least facultatively, in the species.

Apomixis was first reported in Sarcococca ruscifolia (Orr, 1923), and a number of studies listed in the work by Nygren (1954) followed that confirmed adventive embryony (nucellary polyembryony) in several other species of Sarcococca. More recent studies have provided more in-depth studies to document specific mechanisms and activities during the process of apomixis in Sarcococca (e.g., Naumova, 1979; 1980; Naumova and Willemse, 1983)

Seedlings arising through apomixis are genetically identical to the seed parent and, in cases of polyembryony, when one seedling is sexually derived and one or more seedlings develop through apomixis, it can be difficult to identify the sexually derived seedling. Regardless of the mode of apomixis, this phenomenon presents a major obstacle to traditional breeding. Based on the presence of apomixis in the genus and our observations of polyembryony, we chose to introduce variation in this species using mutagenesis.

Mutation breeding is an important tool to improve plants exhibiting apomixis (Lapins, 1983). Although $S$. confusa appears to be a facultative apomict, it is inefficient and cumbersome to identify and separate sexually derived seedlings from nucellar embryos. As such, the objectives of our study were 1) to expose seeds of $S$. confusa to EMS at varying concentrations and exposure durations to evaluate the effects on seed germination, 2) to evaluate growth effects from various treatments, and 3) to determine whether the relative frequency of polyembryony is affected by EMS treatment.

\section{Materials and Methods}

Plant material and experiment design. Mature fruit of $S$. confusa were collected on 10 Dec. 2009 from established plants on the campus of OSU (Corvallis, OR). Fruit were stored in plastic bags at $4{ }^{\circ} \mathrm{C}$ until mutation treatments were initiated. The study consisted of five EMS concentrations $(0 \%$, $0.2 \%, 0.4 \%, 0.8 \%$, and $1.2 \%$ ) with two treatment durations ( 24 and $48 \mathrm{~h}$ ) and was arranged in a completely randomized design.

Mutation treatments. On 15 Feb. 2010, the pericarp was removed manually from seedlings of sweetbox grew true to parent. This anecdotal observation homozygous plant resulting in a homogenous pulation or 2) apomixis. During early pr. iminary studies, seeds sown from openpollinated plants of $S$. confusa at Oregon State University (OSU) resulted in one, two, or three seedlings (Fig. 1), indicating apo-
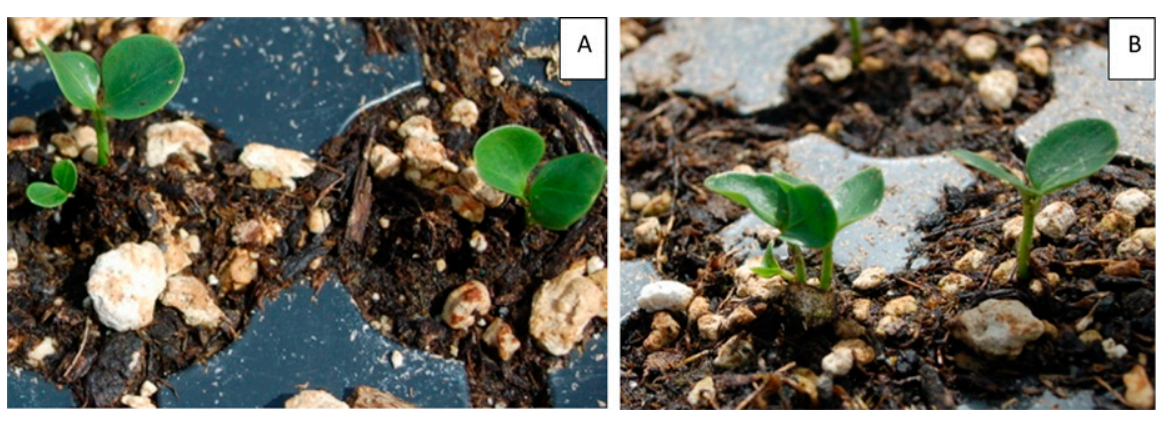

Fig. 1. Germinating seedlings of Sarcococca confusa sown as a single seed in each cell, showing (A) one or two seedlings and (B) one or three seedlings, demonstrating the presence of polyembryony. 


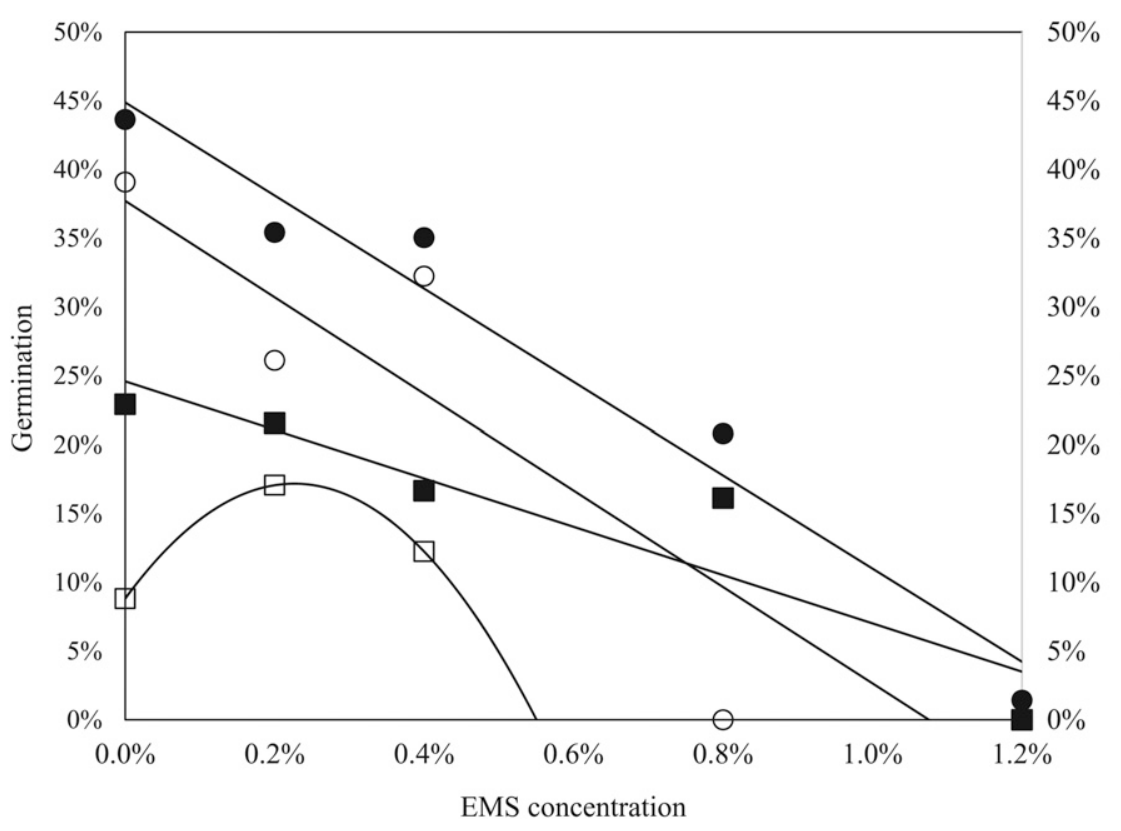

Fig. 2. Germination and twinning percentages of Sarcococca confusa when seeds were exposed to increasing concentrations of ethyl methanesulfonate (EMS) for 24 and $48 \mathrm{~h}$. Percent germination of seeds treated for $24 \mathrm{~h}\left(\mathbf{O} ; y=-33.878 x+0.4488 ; r^{2}=0.9642\right)$ and $48 \mathrm{~h}\left(\bigcirc ; y=-35.072 x+0.3772 ; r^{2}=\right.$ $0.8456)$, and the percentage of twins that occurred among germinated seeds treated for $24 \mathrm{~h}($ $\left.y=-17.567 x+0.2459 ; r^{2}=0.8579\right)$ and $48 \mathrm{~h}\left(\square ; y=-16,347 x^{2}+73.943 \mathrm{x}+0.0882 ; r^{2}=1\right)$.

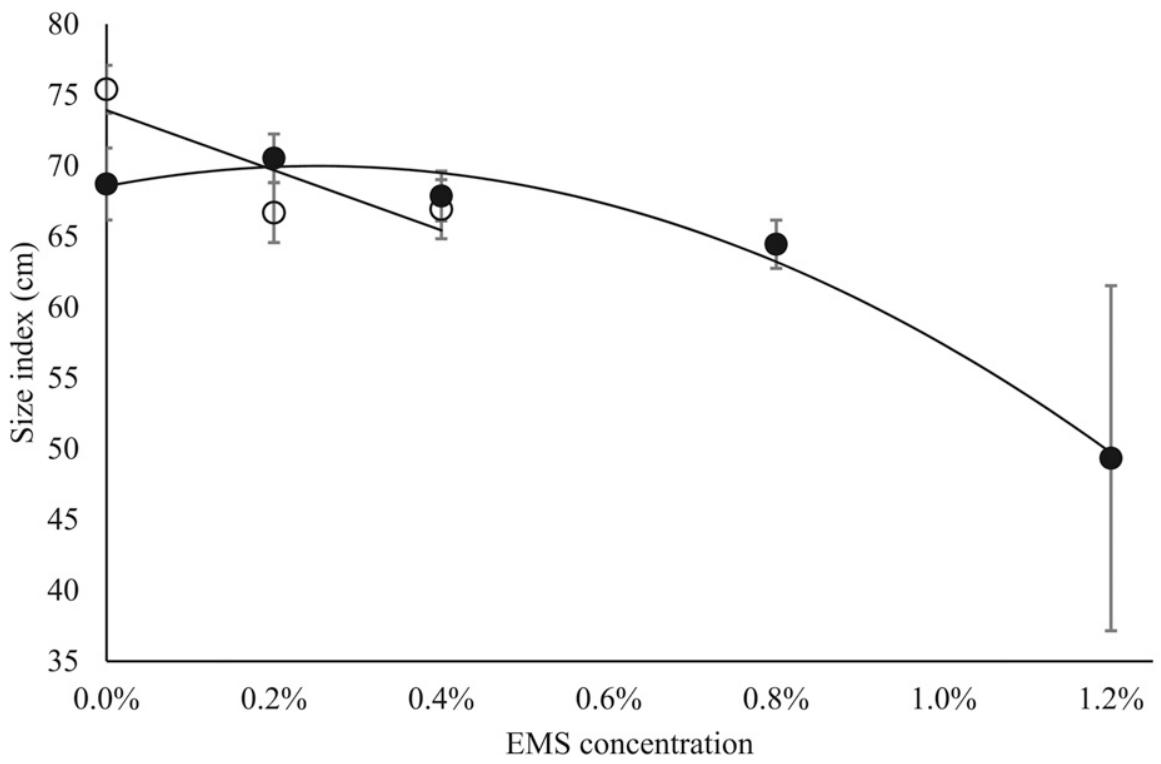

Fig. 3. Size index $\left[\mathrm{SI}=\left(\text { Height } \times \mathrm{Width}_{1} \times \mathrm{Width}_{2}\right)^{1 / 3}\right]$ of 4-year-old Sarcococca confusa plants derived from seed exposed to increasing concentrations of ethyl methanesulfonate (EMS) for $24 \mathrm{~h}(\mathbf{0} ; y=$ $\left.-225,318 x^{2}+1135.1 x+68.551 ; r^{2}=0.984\right)$ and $48 \mathrm{~h}\left(O ; y=-2118.2 x+73.91 ; r^{2}=0.7285\right)$. Plants had been grown for three seasons in containers and one in a field.

seed immediately before treatment. Seeds were separated into groups according to treatment and placed in 500-mL Erlenmeyer flasks with $1 \mathrm{~mL} / \mathrm{seed}$ of a solution containing EMS at the respective concentration in a $0.1 \mathrm{M}$ phosphate buffer. Flasks were sealed with parafilm and seeds were soaked while agitating at $125 \mathrm{rpm}$ at $20^{\circ} \mathrm{C}$ for 24 and $48 \mathrm{~h}$. After treatment, seeds were rinsed under running tap water for $15 \mathrm{~min}$ and sown into 72-cell trays using Sunshine LA4 P potting mix (Sun Gro Horticulture, Agawam, MA) limestone; Patio Potting Soil; Rexius Inc., Eugene, OR) and unaged douglas fir bark mulch (Rexius Inc.). Containers were topdressed with the label rate of $18 \mathrm{~N}-2.6 \mathrm{P}-10 \mathrm{~K}$ controlled-release fertilizer (CRF; APEX, 10-11 month, J.R. Simplot, Boise, ID). On 29 Dec. 2010, plants were transplanted into 3.8-L containers using the same 1:1 substrate blend just described and then top-dressed with the label rate of the same CRF. On 21 Apr. 2011, plants were transplanted into 11.4-L containers filled with the same $1: 1$ substrate blend described earlier and then top-dressed with the same CRF at the label rate. Plants were moved to a $47 \%$ shade house at the OSU Lewis-Brown Farm (Corvallis, OR) and irrigated for $20 \mathrm{~min}$ daily using 12 $\mathrm{L} \cdot \mathrm{h}^{-1}$ spray stakes (Netafim USA Inc., Fresno, CA). Plants were grown there for two seasons, overwintered in a poly-covered greenhouse, and field-planted under a $47 \%$ shade structure on 16 Apr. 2013 at the OSU Lewis-Brown Farm.

M2 seed population. Honey bee hives were placed in the poly-covered greenhouse from 7 to $12 \mathrm{Feb} .2012$ (peak flowering) to facilitate pollination. Up to 14 mature fruit per plant were collected on 14 Jan. 2013 from all plants that bore fruit. This included six plants from the $0 \%$ EMS 24-h treatment, five plants from the $0 \%$ EMS 48 -h treatment, 12 plants from the $0.2 \%$ EMS 24-h treatment, four plants from the $0.2 \%$ 48-h treatment, three plants from the $0.4 \%$ EMS $24-\mathrm{h}$ treatment, and three plants from the $0.4 \%$ 48-h treatment. On $16 \mathrm{Jan}$. 2013, pericarps were removed and seeds were sown in 1.3-L containers filled with Metro Mix 840PC (Sun Gro Horticulture), which were then placed in a glasshouse with day/night set temperatures of $24^{\circ} \mathrm{C} / 17^{\circ} \mathrm{C}$, with a 14 -h photoperiod until germination. Final germination data were collected the first week of July 2013.

Data collection and analysis. The number of germinated seedlings and the occurrence of twinning (i.e., two seedlings derived from one seed) were recorded on 20 July 2010 before they were transplanted to $0.6-\mathrm{L}$ containers. Germination percentage was calculated relative to the number of seedlings sown in each treatment. Twinning percentages were calculated relative to the number of germinated seedlings per treatment. SI [SI = $\left.\left(\text { Height } \times \text { Width }_{1} \times \text { Width }_{2}\right)^{1 / 3}\right]$ measurements were collected on 5 Nov. 2012 (while in 11.4-L containers) and 14 Oct. 2013 (while field-planted).

The relationship between EMS concentration and percent germination, twinning percentage, and mean SI were subject to either linear or quadratic regression for both 24- and 48-h data sets separately. Percent germination of M2 seed was calculated relative to the quantity sown and was subject to one-way analysis of variance (ANOVA) $(\alpha=$ $0.05)$. The relationship between the percentage of M1 plants that bore fruit after four seasons and the EMS rate was subject to linear regression. All data were analyzed using JMP ${ }^{\circledR}$ Pro Version 13.0.0 (SAS Institute Inc., Cary, NC). 


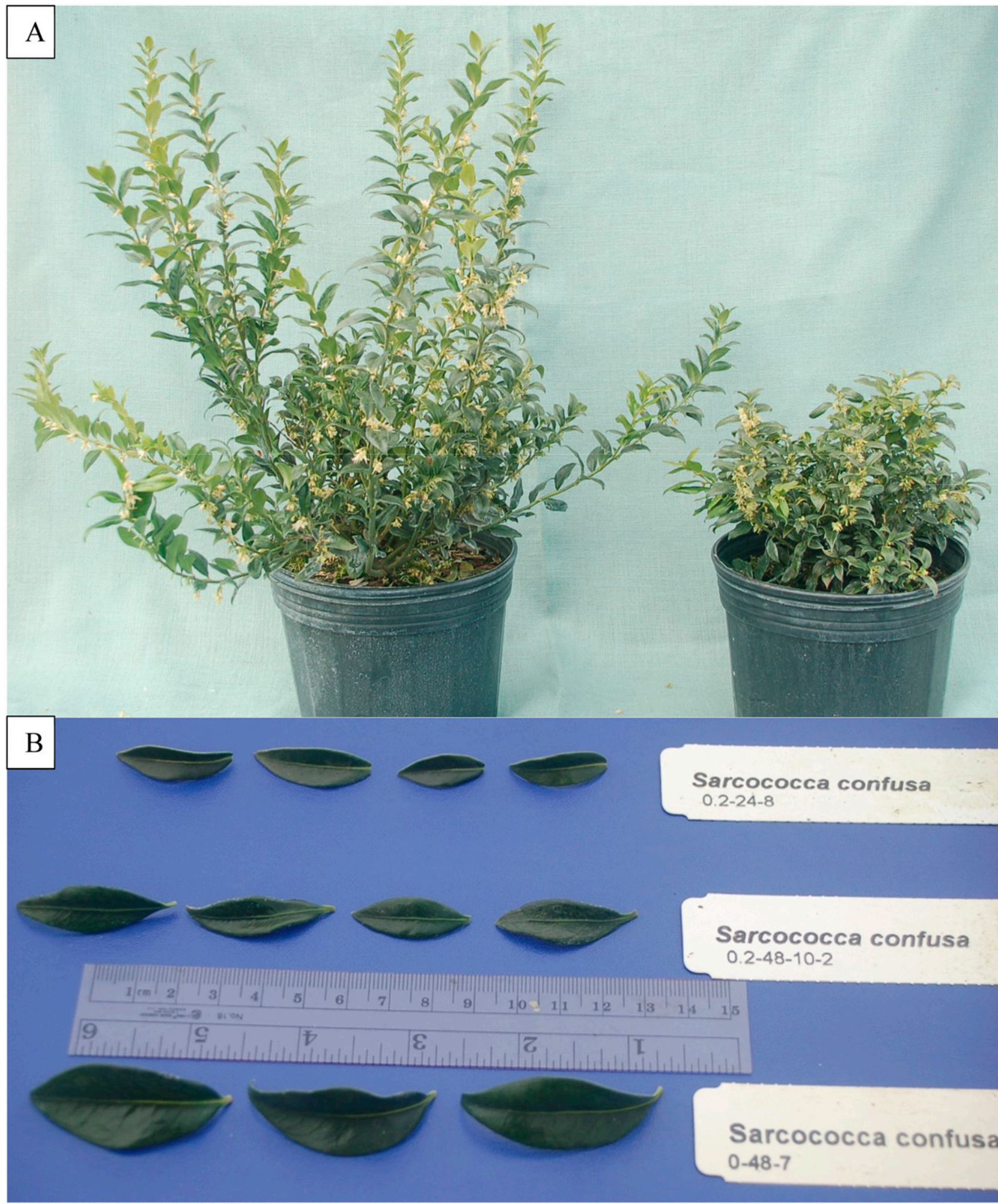

Fig. 4. Exposing seeds of Sarcococca confusa resulted in dwarf mutants and variation in leaf size and shape. (A) Example of size variation between wild-type (left) and dwarf mutant (right). (B) Variation in leaf size and shape between plants exposed to $0.2 \%$ EMS (top and middle) and control (bottom).

\section{Results and Discussion}

Percent germination. A negative linear relationship was observed between percent seed germination and EMS concentration for both the 24- and 48-h treatments $\left(r^{2}=0.9642\right.$ and 0.8456 , respectively). Germination percentage was greatest in the control $(0 \%$ EMS) and decreased as EMS concentration increased (Fig. 2). No germination was observed in the 48 -h treatment with $0.8 \%$ or $1.2 \%$ EMS. Median lethal dose $\left(\mathrm{LD}_{50}\right)$ for the 24- and 48-h treatment groups was $0.66 \%$ and $0.54 \%$ EMS, respectively. Greer and Rinehart (2009) observed a reduction in seed germination percentage of Hydrangea mac- rophylla seed when exposed to $2.5 \%$ or $5 \%$ EMS for $3 \mathrm{~h}$ in the absence of a prior cold treatment; however, cold treatment of both $H$. macrophylla and $H$. paniculata increased tolerance of both species to increasing EMS concentrations. Alcantara et al. (1996) treated Capsicum annuum seed with up to $1.5 \%$ EMS at $20{ }^{\circ} \mathrm{C}$ for $9 \mathrm{~h}$ with no significant 

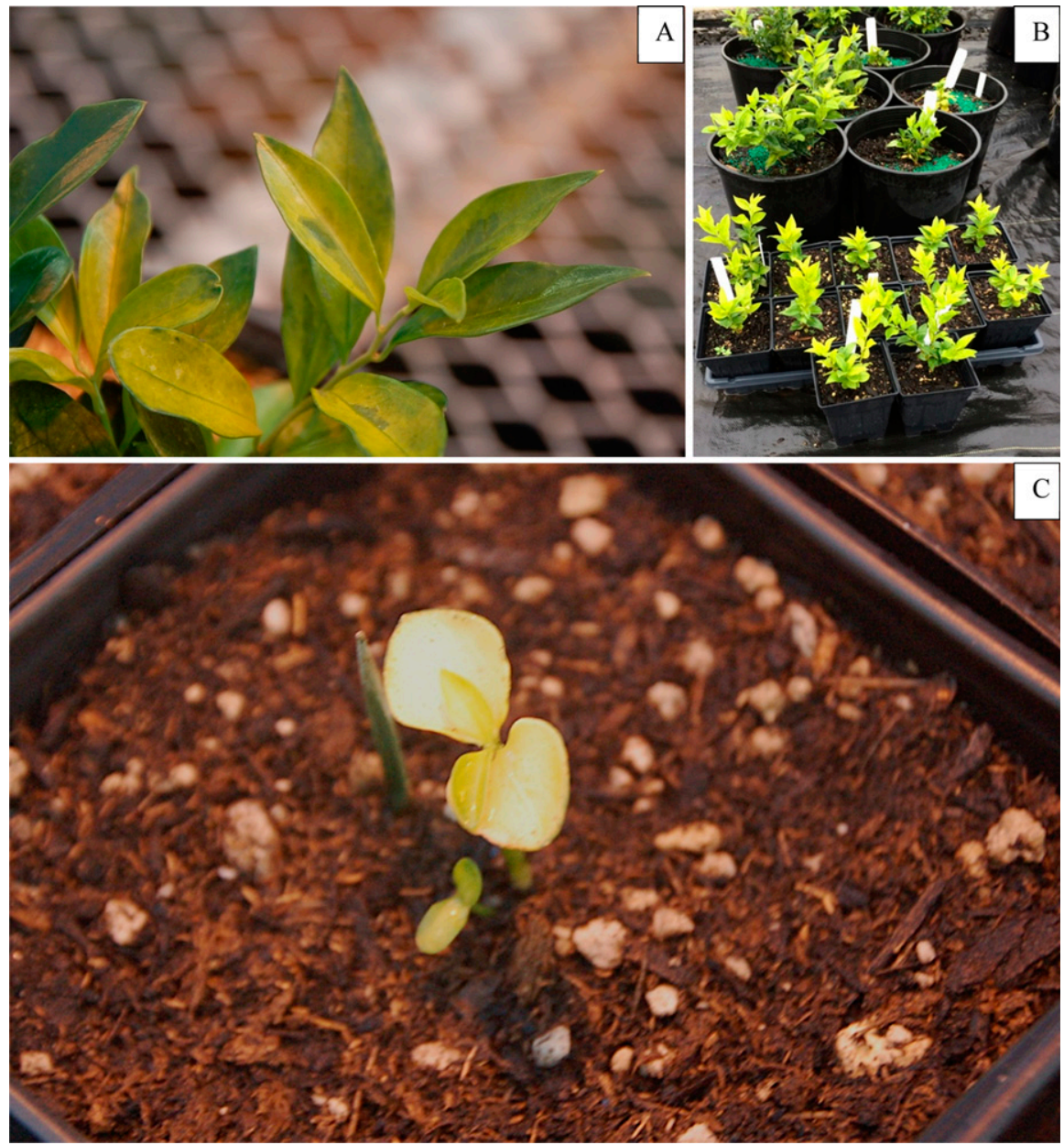

Fig. 5. A chlorophyll-deficient mutant of Sarcococca confusa. (A) Original plant identified with unstable chlorophyll mutation, (B) rooted cuttings collected from the mutant branch and stabilized to a uniform chartreuse color, and (C) seeds collected from branches exhibiting the chartreuse phenotype resulted in seedlings that were uniformly chartreuse and, in this example, also exhibited polyembryony.

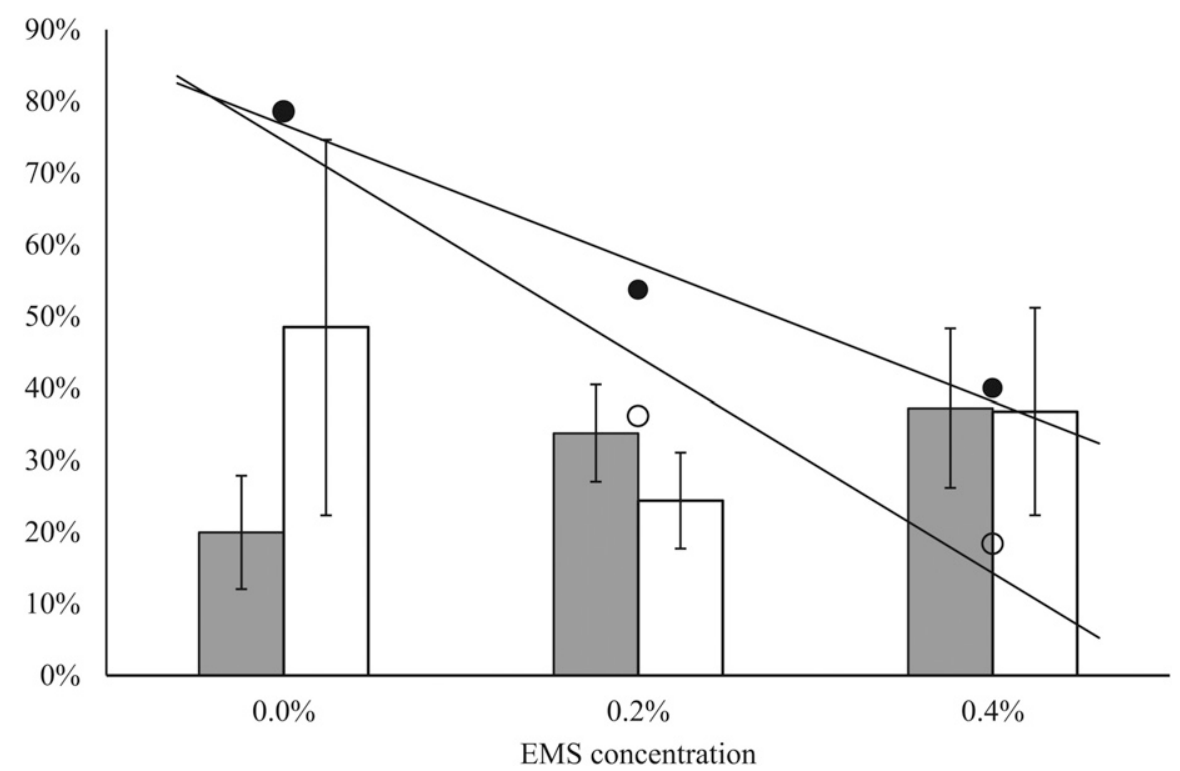

Fig. 6. Percentage of M1 Sarcococca confusa plants that bore fruit four seasons after seeds were treated with increasing concentrations of ethyl methanesulfonate (EMS) for $24 \mathrm{~h}\left(\boldsymbol{O} ; y=-0.1929 x+0.96 ; r^{2}=\right.$ $0.9728)$ and $48 \mathrm{~h}\left(\bigcirc ; y=-0.301 x+1.0457 ; r^{2}=0.9473\right)$, and subsequent average percent germination of M2 seeds collected from fruit-bearing M1 plants from the 24-h (gray bars) and 48-h (white bars) treatments. reduction in germination percentage. Increasing concentration of EMS reduced seed germination of Jatropha curcas from $58 \%$ in the control to $25 \%$ when treated with $4 \%$ EMS (Dhakshanamoorthy et al., 2010).

Twinning. A negative linear relationship was observed between twinning rate and EMS concentration for the 24-h treatment $\left(r^{2}=\right.$ $0.8579)$, where the greatest number of twins was observed in the control, and decreased with greater EMS concentrations (Fig. 2). Twinning percentage in the $48-h$ treatment group was best explained by a quadratic relationship $\left(r^{2}=1\right)$, where the greatest number of twins occurred after exposure to $0.2 \%$ EMS.

Plant size. Plant SI after four growing seasons was explained by a quadratic relationship in the 24-h treatment group $\left(r^{2}=\right.$ 0.984 ), where the greatest SI was observed at $0.2 \%$ EMS and decreased at greater EMS concentrations, although no significant differences were found when comparing treatments using ANOVA $(P=0.153)$ (Fig. 3). Plant SI in the 48-h treatment group was explained by a negative linear relationship. This data set only consisted of three data points, as germination only occurred at $0 \%$, $0.2 \%$, and $0.4 \%$ EMS, and is statistically fit better by a quadratic regression. However, this model would predict a substantial increase in SI if projected to greater EMS concentrations and was therefore deemed biologically irrational. Similar to the 24-h treatment group, no significant differences were found when comparing treatments using ANOVA $(P=0.110)$ Several dwarf plants were identified from treated seeds and show promise as compact plants for home foundation plantings or for use in containers (Fig. 4). Treated plants exhibited altered leaf shape with reduced undulation, narrower leaf blades, and shorter leaf blades (Fig. 4). Dwarfing is a common result of mutagenesis (Lapins, 1983), and a similar reduction in plant size as well as altered leaf morphology has been observed in other taxa. Ribes sanguineum 'Oregon Snowflake' was developed using EMS treatment, which resulted in increased branching, reduced plant height, and altered leaf morphology (Contreras and Friddle, 2015). Greer and Rinehart (2009) recovered dwarf mutants of Hydrangea after treating seeds with EMS, but the frequency and degree of dwarfing was not reported.

Chlorophyll mutant. A portion of one plant exhibited an irregular chlorophyll mutation. This branch was propagated from stem cuttings and later stabilized to a uniform chartreuse color (Fig. 5). Subsequent clonal propagation from stem cuttings has shown this mutation to be stable after three rounds of serial propagation. In addition, seeds were collected from a branch showing the chlorophyll mutation, and seedlings exhibited uniform chartreuse leaf color from the cotyledon stage and at least some seeds were polyembryonic (Fig. 5). Smith and Brand (2012) developed and introduced Buddleja davidii 'Summer Skies', a variegated cultivar of 
butterfly bush that resulted from exposing seeds to EMS. In contrast to the uniform chartreuse chlorophyll mutation we observed, 'Summer Skies' exhibited a marginal variegation with dark-green centers, which the authors presume was a periclinal chimera as a result of its appearance and stability. Greer and Rinehart (2009) reported variegated and chlorotic mutants resulting from seed treatment of Hydrangea with EMS, but no details were included on pattern or prevalence.

M2 seed germination. A negative linear relationship was observed between the percentage of fruit-bearing plants after three growing seasons and EMS rate for both the 24- and 48-h treatment groups, where the greatest percentage of fruit-bearing plants occurred in the absence of EMS; the least percentage was seen in the $0.4 \%$ group (Fig. 6). No fruit was found on M1 plants grown from seeds treated with $0.8 \%$ or $1.2 \%$ EMS. There were no differences in germination percentage of M2 seeds among treatments in the 24- or 48-h treatment groups $(P=0.506$ and 0.526 , respectively).

Apomixis is often associated with polyploidy, as in Cotoneaster, which has a natural ploidy series wherein tetraploids are mostly obligate apomicts and diploids produce sexual progeny (Sax, 1954). Previous reports of apomixis in Sarcococca include both diploids ( $S$. humilis, S. hookeriana) and the tetraploid $S$. ruscifolia (Nygren, 1954). The only prior report in $S$. confusa, which is a tetraploid $(2 n=4 x=56)$ (Denaeghel et al., 2017), is the anecdotal report from Dirr (2009) and our own findings of polyembryony. Sarcococca confusa was used as a pollen parent in crosses with $S$. ruscifolia 'Dragon's Gate', but Denaeghel et al. (2017) did not attempt to use it as a seed parent. They also did not report any evidence of apomixis, and all seedlings in their crossing study had $10 \%$ or greater amplified fragment length polymorphism markers from the male parent, which indicates their progeny were derived sexually (Denaeghel et al., 2017). Although there are conflicting reports of apomixis among various species of Sarcococca, we have repeatedly observed polyembryony among seeds sown, making traditional breeding through sexual recombination of parents challenging and inefficient. Our study demonstrates the utility of chemical mutagenesis to induce useful variation among sweetbox seedlings and to reduce the rate of polyembryony or twinning.

Other studies have investigated the impact of various pretreatments before mutagenesis, such as imbibition or cold treatment. We did not compare any such treatments, but held all seeds at $4{ }^{\circ} \mathrm{C}$ within the pericarp, which presumably provided some degree of cold stratification as a result of the presence of moisture within the fruit. This approach aligns with recommendations made by Lapins (1983). Greer and Rinehart (2009) found that Hydrangea macrophylla and $H$. paniculata were both more tolerant of greater concentrations of EMS after cold treatment. On the other hand, Alcantara et al. (1996) observed no greater tolerance in Capsicum annuum after imbibition before EMS treatment of seeds.

\section{Literature Cited}

Alcantara, T.P., P.W. Bosland, and D.W. Smith. 1996. Ethyl methanesulfonate-induced seed mutagenesis of Capsicum annuит. J. Hered. 87:239-241.
Contreras, R.N. and M.W. Friddle. 2015. 'Oregon Snowflake' flowering currant. HortScience 50:320-321.

Denaeghel, H., K. Van Laere, L. Leus, J. Van Huylenbroeck, and M.-C. Van Labeke. 2017. Interspecific hybridization in Sarcococca supported by analysis of ploidy level, genome size and genetic relationships. Euphytica 213:149.

Dhakshanamoorthy, D., R. Selvaraj, and A. Chidambaram. 2010. Physical and chemical mutagenesis in Jatropha curcas L. to induce variability in seed germination, growth and yield traits. Romanian J. Biol.-Plant Biol. 55:113-125.

Dirr, M.A. 2009. Manual of woody landscape plants: Their identification, ornamental characteristics, culture, propagation and uses. 6th ed. Stipes Publishing, Champaign, IL.

Greer, S.P. and T.A. Rinehart. 2009. In vitro germination and dormancy responses of $\mathrm{Hy}$ drangea macrophylla and Hydrangea paniculata seeds to ethyl methane sulfonate and cold treatment. HortScience 44:764-769.

Lapins, K.O. 1983. Mutation breeding, p. 74-99. In: J.N. Moore and J.J. Janick (eds.). Methods in fruit breeding. Purdue University Press, West Lafayette, IN.

Naumova, T. 1979. Ovule, microsporogenesis, micro- and macrogametogenesis in Sarcococca humilis Hort. (Buxaceae). Bot. Z. 64:635-645.

Naumova, T. 1980. Nucellar polyembryony in Sarcococca (Buxaceae). Bot. Z. 65:230-240.

Naumova, T. and M.T.M. Willemse. 1983. Nucellar polyembryony in Sarcococca humilis: Ultrastructural aspects. Phytomorphology 32:94-108.

Nygren, A. 1954. Apomixis in the angiosperms II. Bot. Rev. 7:507-542.

Orr, W.J. 1923. Polyembryony in Sarcococca ruscifolia Stapf. R. Bot. Gard. Edinburgh. Notes 14:21-23.

Sax, H.J. 1954. Polyploidy and apomixis in $\mathrm{Co}$ toneaster. J. Arnold Arbor. 35:334-365.

Smith, W.A. and M.H. Brand. 2012. 'Summer Skies' Buddleja davidii. HortScience 47:126127. 